\title{
Amateur Basketball Participants Earnings and Cost Analytic Research
}

\author{
Tao Lv and Wen $\mathrm{Ji}^{*}$
}

Department of Physical Education, Hohai University, Nanjing 210098, Jiangsu, China

\begin{abstract}
Chinese amateur basketball undertaking is an important part in Chinese basketball undertaking, amateur team reserves talents for Chinese professional basketball team and ensure its normal and stable development. The paper carries on statistical analysis of results that are obtained by interviewing, it finds that among experts in this survey, professors occupy $41.7 \%$, associate professors occupy $33.3 \%$. And meanwhile, it analyzes experts reform situation on recent years Chinese amateur basketball undertaking, and finds that nearly $66.7 \%$ experts think that recent years amateur basketball undertaking reformation direction and methods conform to contemporary national conditions, but it still has drawbacks, China should reference successful experiences from foreign reformation so that propels to Chinese amateur basketball undertaking development; by establishing relevant mathematical model, utilizing fuzzy AHP method, it makes quantitative analysis of factors that affect Chinese amateur basketball undertaking development, and puts forward that among the amount of amateur athletes, national investment, athletes consumption situation, participants purposes, participants income these six influential factors, amount of amateur athletes participants is most important factor that affects Chinese amateur basketball undertaking development, its weight is $31.4 \%$, therefore China should increase publicity regarding amateur basketball activity's important effects on improving physical quality, and then let more residents to participate in them.
\end{abstract}

Keywords: Amateur basketball, Fuzzy AHP method, Sports industry, Mathematical model, Physical quality.

\section{INTRODUCTION}

As group that is fond of basketball have gradually increased, Chinese amateur basketball team has unprecedented developed and relative experts also obtain outstanding research achievements in the field. Yan Xiao-Qi in the article "Liaoning province amateur basketball athletes training engagement motivations sociological analysis", he carried on research on Chinese Liaoning province amateur basketball athletes training motivations, and found that among these athletes, a large part of people had their fixed income, and freelances were more, these people spent spare time and meanwhile improved physical quality, which was uppermost motivation in these group, secondly, there were some people that made acquaintance with many friends by participating in basketball, which built foundations for future enterprises development [1]. Teng Teng in 'Xi' an amateur basketball competitions market consumption demands analytic research", he utilized multiple methods, through interviewing and investigating, consulting lots of documents literature, carried out research on $\mathrm{Xi}^{\prime}$ an amateur basketball market development on the basis of combining with formers researches, and got that many people would participate in amateur basketball club, and they would purchase their favorite basketball teams' team shirts, which stimulated resident consumption and meanwhile raised lots of funds for Chinese basketball undertaking development [2]. The article thought that it should increase investment in Chinese amateur basketball teams so that propel to their rapid development [3]. Ju Yuan-Zhi in the article "Research on Jinan amateur basketball organizational situation and development mechanism", he researched on Chinese Jinan amateur basketball organization situation, and pointed out that Jinan amateur basketball undertaking was in rapid development, which had commonalities with others, but it also had its own superiorities in development and operation aspects. And while researched on amateur basketball development, it also reflected Jinan basketball clubs development situation and trends, which provided potential consumption groups for expanding Chinese consumption market space [4].

Through interviewing and investigating relevant scholars, consulting relevant information, and utilizing mathematical models, the paper proceeds with analysis and research on Chinese amateur basketball undertaking development [5].

Entering into $21^{\text {st }}$ century, Chinese living standards basically arrive at well-off, Chinese residents are well-fed and well-clothed, they own many leisure time after work. In terms of time dimension, Chinese science and technology has been rapid developed, mechanization level arrives at unprecedented scale, therefore it is possible to let weary people to get rid of handicraft industry and participate in leisure life [6]. Therefore, Chinese residents have their own thoughts on how to enrich leisure life, amateur basketball as an important part in leisure sports life is contemporary people's first choice. Basketball has gradually developed into comprehensive competitive sports activity with 
connotation, techniques, criterions and tactics from simple games, and due to its rich connotation, intense fighting and other features, is favored by whole world residents. According to incomplete statistics, contemporary society has nearly 0.5 billion residents that participate in basketball, and people watch basketball games are even out of count. In China, population that participates in amateur basketball accounts for $25 \%$ of totality, but due to culture differences, basketball later arose in China, therefore no matter professional basketball, amateur basketball or basketball clubs development, all suffer greatly influences.

Therefore, the paper researches on Chinese amateur basketball undertaking development status under contemporary circumstance, and further finds main factors that hinder Chinese basketball undertaking development, and then solve them one by one to clear away obstacles, break through bottlenecks for Chinese basketball undertaking development and finally let it to get on express train.

\section{MODEL ESTABLISHMENT}

By recent years relevant experts research on mathematical models, they find that mathematical models can solve problems that cannot solve in real life. AHP is just gathering up several relative correlated factors and using relative software to calculate them so that get factor that has largest correlation degree.

\subsection{Analyze Investigated Objects Situation}

By visiting nationwide partial important cities, the paper interviews contemporary amateur basketball experts in all fields, carries out analysis of Chinese amateur basketball undertaking development, and proceeds with list analysis of collected data. Below Table $\mathbf{1}$ is statistical table about the paper interviewed experts and scholars.
By above Table 1 and broken line (Fig. 1), it carries out investigation and research on the paper interviewed professors, associate professors and bureau leaders, finds that the number of professors are five that is the most in interviewed experts, which accounts for $41.7 \%$, due to experts in China that particularly researches on Chinese amateur basketball undertaking are very few, therefore the paper interviewed five professors add some strength for the paper.

Besides, the paper has the honor to interview Chinese bureau leaders that cautious and conscientious dedicate for Chinese sports undertaking in sports field, these people are executors of Chinese sports undertaking reformation.

Table 2 is interviewed experts evaluation on Chinese amateur basketball reformation, from which eight experts think that Chinese amateur basketball reformation is adapted to national conditions of Chinese construction of socialist under contemporary circumstance.

Sports undertaking reformation is a project that has a long way to go, which cannot be expected to fulfill in one day but is a process that needs to do step by step and move in circles, through researching sports undertaking development stages, finding out problems and further solving problems, which is a sustainable path that most suitable to Chinese sports undertaking development.

\subsection{Amateur Basketball Players' Situation}

Chinese amateur players participate in basketball exercising in spare time, enrich their leisure life, and improve their physical quality; below Table $\mathbf{3}$ is analysis of Chinese amateur basketball players' weekly basketball exercises engagement.

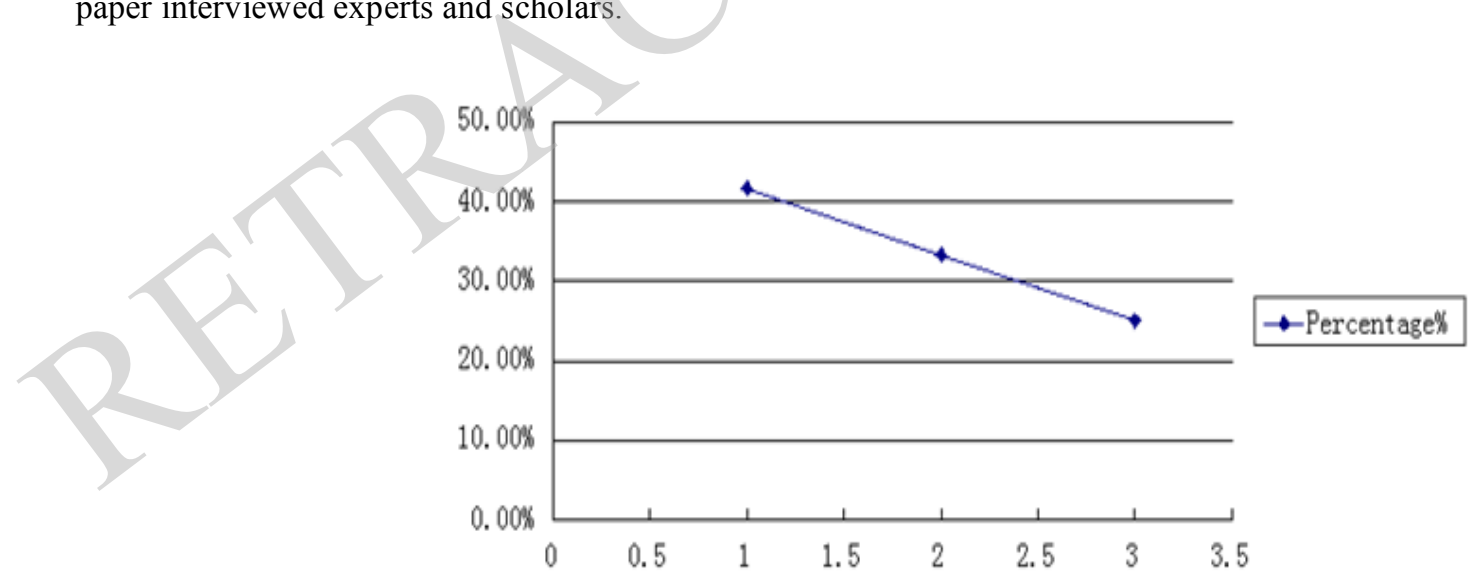

Fig. (1). In this article investigation by the experts who are analyzed.

Table 1. Analyze the paper investigated experts constitution.

\begin{tabular}{|c|c|c|c|c|}
\hline Experts constitution & Professor & Associate professor & Bureau leader & Total (People) \\
\hline \hline Frequency & 5 & 4 & 3 & 12 \\
\hline Percentage $\%$ & $41.7 \%$ & $33.3 \%$ & $25 \%$ & 0 \\
\hline
\end{tabular}


Table 2. Expert evaluation statistical table.

\begin{tabular}{|c|c|c|c|c|c|}
\hline & Quite appropriate & Appropriate & Basic appropriate & Inappropriate & Quite inappropriate \\
\hline \hline Frequency & 2 & 8 & 2 & 0 & 0 \\
\hline Proportion\% & $16.7 \%$ & $66.7 \%$ & $16.7 \%$ & 0 & 0 \\
\hline
\end{tabular}

Table 3. Weekly basketball exercising engagement times.

\begin{tabular}{|c|c|c|c|c|}
\hline & Less than one time & 1-2 times & K-4 times & 5-6 times \\
& 45 & 473 & 457 & 83 \\
\hline \hline Frequency & $4.2 \%$ & $39.0 \%$ & $37 \%$ & $6.2 \%$ \\
\hline Proportion $\%$ & $174 \%$ & $12.8 \%$ \\
\hline
\end{tabular}

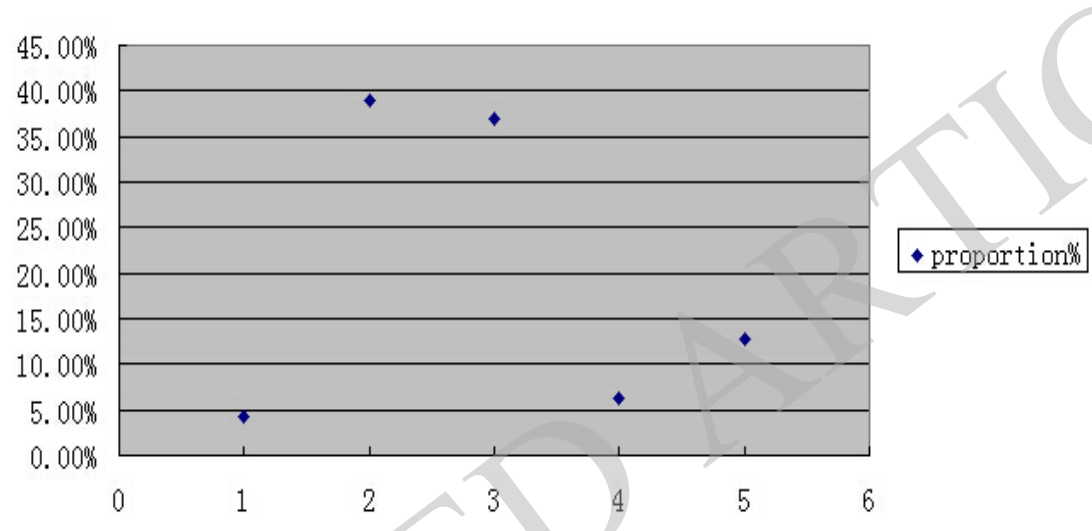

Fig. (2). In basketball exercise number of times a week.

By above dotted (Fig. 2) analysis, it finds that participants who take basketball exercises for one to two times per week account for $39 \%$, next is the ones that take three to four times per week and occupy $37 \%$, which indicates Chinese resident makes full use of spare time, enhances their physique to provide talented person for Chinese basketball undertaking.

Fuzzy comprehensive evaluation method-based amateur basketball undertaking development and research

Define evaluation indicator set, according to:

$U=\left\{u_{1}, u_{2}, \ldots, u_{m}\right\}, m=1,2,3, \ldots, 6$

Evaluation indicator set is $=\{$ the number of amateur athletes, state investment, athlete consumption situation, athlete age, participant purpose, participant income\} .

Define evaluation grade set, when research on Chinese amateur basketball undertaking development, it utilizes expert evaluation method to define evaluation grade set. According to: $V=\left\{v_{1}, v_{2}, \cdots, v_{n}\right\}, n=1,2,3,4$

Amateur basketball undertaking mode evaluation grade set is $=\{$ Quite appropriate, appropriate, ordinary, inappropriate\}.

Define each evaluation indicator weight, weight main expression method is: $U=\left\{\mu_{1}, \mu_{2}, \ldots, \mu_{m}\right\}, m=1,2,3, \ldots, 6$.
Among them, $w_{i}$ is evaluation parameter $i$ monitoring value; $\overline{S_{i}}$ is evaluation parameter $i$ grade $m$ criterion arithmetic average value, then weight set is: $w=\left\{w_{1}, w_{2}, \cdots, w_{m}\right\}$.

Here, apply normalization method to calculate weights, amateur basketball undertaking evaluation indicator weight is: $w=\{0.13,0.24,0.12,0.34,0.14,0.08\}$

AHP method-based Chinese amateur basketball undertaking evaluation matrix

Comprehensive evaluation matrix $R$ evaluation methods mainly have expert evaluation method, analytic hierarchy process, and membership function method.

Here, it uses analytic hierarchy process, defines fuzzy relation matrix $R$, from which:

$R=\left(R_{1}, \quad R_{2}, \quad R_{3}, \quad R_{4}, \quad R_{5}, \quad R_{6}\right)^{T}$

AHP method guiding thought:

(1) Establish hierarchical structure

Target layer: Amateur basketball undertaking reformation satisfaction

Criterion layer: Scheme influence factors, $C_{1}$ is the number of amateur athletes, $C_{2}$ is state investment, $C_{3}$ is athlete consumption situation, $C_{4}$ is participant age, $C_{5}$ is participant purpose, $C_{6}$ is participant income. 
Scheme layer: $A_{1}$ is quite appropriate, $A_{2}$ is appropriate, $A_{3}$ is ordinary, $A_{4}$ is inappropriate.

(2) Construct paired comparison matrix

Here apply operational research expert proposed 1 9 ratio scale. as:

According to above scale Table 4, set judgment matrix $A$

$$
A=\left(\begin{array}{cccccc}
2 & 3 & \frac{1}{4} & \frac{1}{5} & \frac{1}{3} & \frac{1}{2} \\
\frac{1}{4} & 2 & \frac{1}{3} & \frac{1}{2} & \frac{1}{4} & \frac{1}{5} \\
2 & 5 & 1 & 3 & 6 & 4 \\
5 & 2 & \frac{1}{3} & 1 & 3 & 7 \\
4 & 5 & \frac{1}{4} & \frac{1}{3} & 1 & \frac{1}{4} \\
1 & 2 & \frac{1}{4} & \frac{1}{2} & 5 & 2
\end{array}\right)
$$

Table 4. 1 9 scale definition.

\begin{tabular}{|c|c|}
\hline Scale $\boldsymbol{\alpha}_{i j}$ & Definition \\
\hline \hline 1 & Factor $\mathrm{i}$ and factor $\mathrm{j}$ have equal importance \\
\hline 3 & Factor $\mathrm{i}$ is slightly more important than factor $\mathrm{j}$ \\
\hline 5 & Factor $\mathrm{i}$ is relative more important than factor $\mathrm{j}$ \\
\hline 7 & Factor $\mathrm{i}$ is extremely more important than factor $\mathrm{j}$ \\
\hline 9 & Factor $\mathrm{i}$ is absolute more important than factor $\mathrm{j}$ \\
\hline $2,4,6,8$ & Indicates middle state corresponding scale value of \\
& above judgments \\
\hline
\end{tabular}

And constructed all scheme layer judgment matrixes correspond to different criterion layers are as following Tables 5-7.

\section{(3) Calculate weight}

To judgment matrix $A$

Firstly use MATLAB software to make following processing:
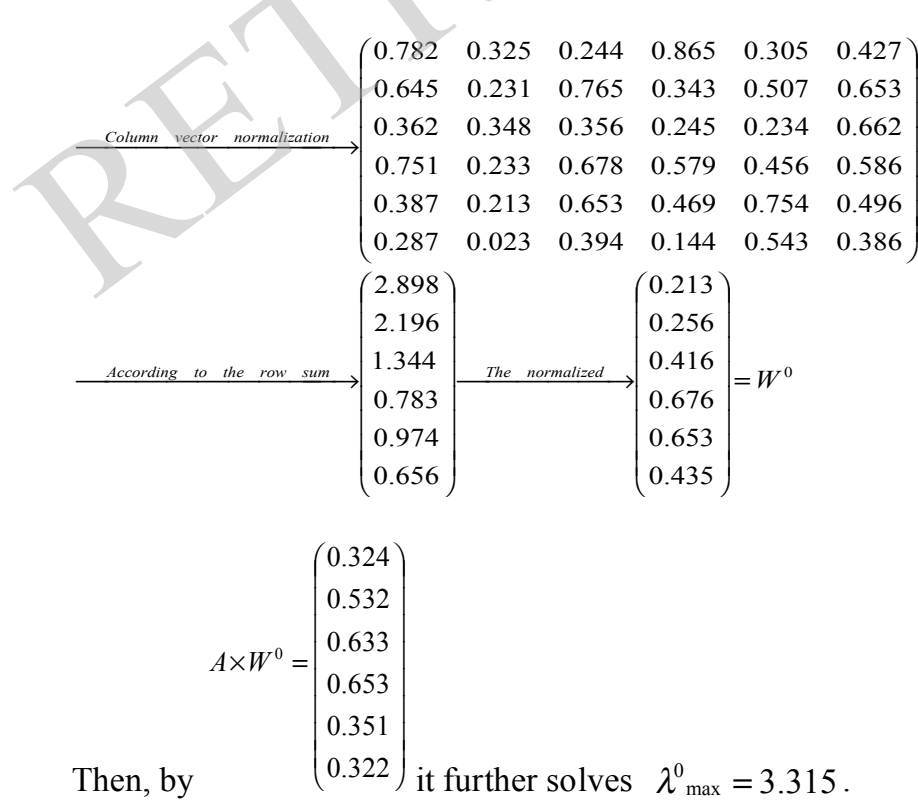

Similarly, criterion layer judgment matrix corresponding maximum feature value and feature vector are successively:

$\lambda^{(1)}{ }_{\max }=1.772, \omega_{1}{ }^{1}=\left(\begin{array}{c}0.325 \\ 0.375 \\ 0.857 \\ 0.295 \\ 0.683 \\ 0.783\end{array}\right) ; \lambda^{(2)}{ }_{\max }=2.756, \omega_{2}{ }^{1}=\left(\begin{array}{c}0.232 \\ 0.046 \\ 0.783 \\ 0.864 \\ 0.396 \\ 0.353\end{array}\right)$;

$\lambda^{(3)}{ }_{\max }=2.679, \omega_{3}{ }^{1}=\left(\begin{array}{l}0.303 \\ 0.157 \\ 0.764 \\ 0.639 \\ 0.644 \\ 0.927\end{array}\right) ; \quad \lambda^{(4)}{ }_{\max }=3.041, \omega_{4}{ }^{1}=\left(\begin{array}{l}0.326 \\ 0.532 \\ 0.778 \\ 0.865 \\ 0.756 \\ 0.345\end{array}\right)$;

$\lambda_{\text {max }}^{(5)}=2.774, \omega_{5}{ }^{1}=\left(\begin{array}{l}0.342 \\ 0.642 \\ 0.844 \\ 0.763 \\ 0.573 \\ 0.683\end{array}\right) ; \lambda^{(6)}{ }_{\text {max }}=2.743, \omega_{6}{ }^{1}=\left(\begin{array}{l}0.324 \\ 0.342 \\ 0.564 \\ 0.768 \\ 0.445 \\ 0.435\end{array}\right)$

By above computed results, it is clear:

It can get comprehensive evaluation matrix as following:

$$
R=\left(\begin{array}{llllll}
0.674 & 0.112 & 0.406 & 0.406 & 0.323 & 0.441 \\
0.243 & 0.057 & 0.146 & 0.251 & 0.345 & 0.242 \\
0.856 & 0.872 & 0.875 & 0.885 & 0.765 & 0.345 \\
0.745 & 0.761 & 0.769 & 0.741 & 0.751 & 0.765 \\
0.345 & 0.595 & 0.654 & 0.621 & 0.624 & 0.345 \\
0.754 & 0.385 & 0.527 & 0.557 & 0.547 & 0.344
\end{array}\right)
$$

Known $W=\left(\mu_{j}\right)_{1 \times m}, R=\left(r_{j i}\right)_{m \times n}$, by:

$$
S=w \circ R=\left(\mu_{1}, \mu_{2}, \cdots, \mu_{m}\right) \circ\left(\begin{array}{cccc}
r_{11} & r_{12} & \cdots & r_{1 n} \\
r_{21} & r_{22} & \cdots & r_{2 n} \\
\vdots & \vdots & \vdots & \vdots \\
r_{m 1} & r_{m 2} & \cdots & r_{m n}
\end{array}\right)=\left(s_{1}, s_{2}, \cdots, s_{n}\right)
$$

It can get fuzzy evaluation set $S$, which is:

$s_{k}=\min \left(1, \sum_{j=1}^{m} \mu_{j} r_{j k}\right), k=1,2, \cdots, n$ get:

Input above computed result into above formula, it can $S=\left(\begin{array}{llllll}0.125, & 0.113, & 0.357, & 0.339, & 0.288 & 0.241\end{array}\right)$

By analyzing fuzzy evaluation vector $S$, it makes comprehensive conclusion. Generally, it can adopt maximum membership principle, weighted average principle, fuzzy vector uniformization, and here apply maximum membership principle. By $s=(0.095,0.083,0.267,0.271$, $0.158,0.126)$, it is clear: 
Table 5. Criterion layer judgment matrix $\mathrm{C1}$.

\begin{tabular}{|c|c|c|c|c|c|c|c|c|c|}
\hline $\boldsymbol{C}_{\mathbf{1}}$ & $\boldsymbol{A}_{\mathbf{1}}$ & $\boldsymbol{A}_{\mathbf{2}}$ & $\boldsymbol{A}_{\mathbf{3}}$ & $\boldsymbol{A}_{\mathbf{4}}$ & $\boldsymbol{C}_{\mathbf{2}}$ & $\boldsymbol{A}_{\mathbf{1}}$ & $\boldsymbol{A}_{\mathbf{2}}$ & $\boldsymbol{A}_{\mathbf{3}}$ & $\boldsymbol{A}_{\mathbf{4}}$ \\
\hline \hline$A_{1}$ & 3 & 2 & 5 & 6 & $A_{1}$ & 3 & 3 & 2 \\
\hline$A_{2}$ & $1 / 2$ & 2 & 3 & 4 & $A_{2}$ & $1 / 3$ & 2 & 3 \\
\hline$A_{3}$ & $1 / 3$ & $1 / 4$ & 6 & 3 & $A_{3}$ & $1 / 2$ & $1 / 7$ & 4 \\
\hline$A_{4}$ & $1 / 2$ & $1 / 3$ & $1 / 2$ & 1 & $A_{4}$ & $1 / 6$ & $1 / 4$ & $1 / 2$ & 3 \\
\hline
\end{tabular}

Table 6. Criterion layer judgment matrix C3.

\begin{tabular}{|c|c|c|c|c|c|c|c|c|}
\hline $\boldsymbol{C}_{\mathbf{3}}$ & $\boldsymbol{A}_{\mathbf{1}}$ & $\boldsymbol{A}_{\mathbf{2}}$ & $\boldsymbol{A}_{\mathbf{3}}$ & $\boldsymbol{A}_{\mathbf{4}}$ & $\boldsymbol{C}_{\mathbf{4}}$ & $\boldsymbol{A}_{\mathbf{1}}$ & $\boldsymbol{A}_{\mathbf{2}}$ & $\boldsymbol{A}_{\mathbf{3}}$ \\
\hline \hline$A_{1}$ & 3 & 3 & 3 & 3 & $A_{1}$ & 2 & 5 & 2 \\
\hline$A_{2}$ & $1 / 4$ & 2 & 6 & 4 & $A_{2}$ & $1 / 2$ & 3 & 3 \\
\hline$A_{3}$ & $1 / 2$ & $1 / 4$ & 2 & $1 / 7$ & $A_{3}$ & $1 / 4$ & $1 / 2$ & 4 \\
\hline$A_{4}$ & $1 / 6$ & $1 / 6$ & 4 & 2 & $A_{4}$ & $1 / 5$ & $1 / 6$ & 3 \\
\hline
\end{tabular}

Table 7. Criterion layer judgment matrix A3.

\begin{tabular}{|c|c|c|c|c|c|c|c|c|c|}
\hline $\boldsymbol{C}_{\mathbf{5}}$ & $\boldsymbol{A}_{\mathbf{1}}$ & $\boldsymbol{A}_{\mathbf{2}}$ & $\boldsymbol{A}_{\mathbf{3}}$ & $\boldsymbol{A}_{\mathbf{4}}$ & $\boldsymbol{C}_{\mathbf{6}}$ & $\boldsymbol{A}_{\mathbf{1}}$ & $\boldsymbol{A}_{\mathbf{2}}$ & $\boldsymbol{A}_{\mathbf{3}}$ & $\boldsymbol{A}_{\mathbf{4}}$ \\
\hline \hline$A_{1}$ & 6 & 3 & 3 & 4 & $A_{1}$ & 1 & 3 & 4 \\
\hline$A_{2}$ & $1 / 2$ & 2 & 2 & 3 & $A_{2}$ & $1 / 3$ & 1 & 3 \\
\hline$A_{3}$ & $1 / 4$ & $1 / 3$ & 1 & $1 / 3$ & $A_{3}$ & $1 / 5$ & $1 / 3$ & 3 \\
\hline$A_{4}$ & $1 / 2$ & $1 / 3$ & 3 & 1 & $A_{4}$ & $1 / 6$ & $1 / 7$ & 2 \\
\hline
\end{tabular}

Table 8. Chinese amateur basketball undertaking development weight comparison table.

\begin{tabular}{|c|c|c|c|c|c|c|}
\hline & $\begin{array}{c}\text { The number of } \\
\text { amateur athletes }\end{array}$ & State investment & $\begin{array}{c}\text { Athlete consumption } \\
\text { situation }\end{array}$ & Athlete age & $\begin{array}{c}\text { Participant } \\
\text { purposes }\end{array}$ & $\begin{array}{c}\text { Participant } \\
\text { income }\end{array}$ \\
\hline \hline Weight & $31.4 \%$ & $10.5 \%$ & $22.4 \%$ & $6.9 \%$ & $14.8 \%$ & $14.6 \%$ \\
\hline
\end{tabular}

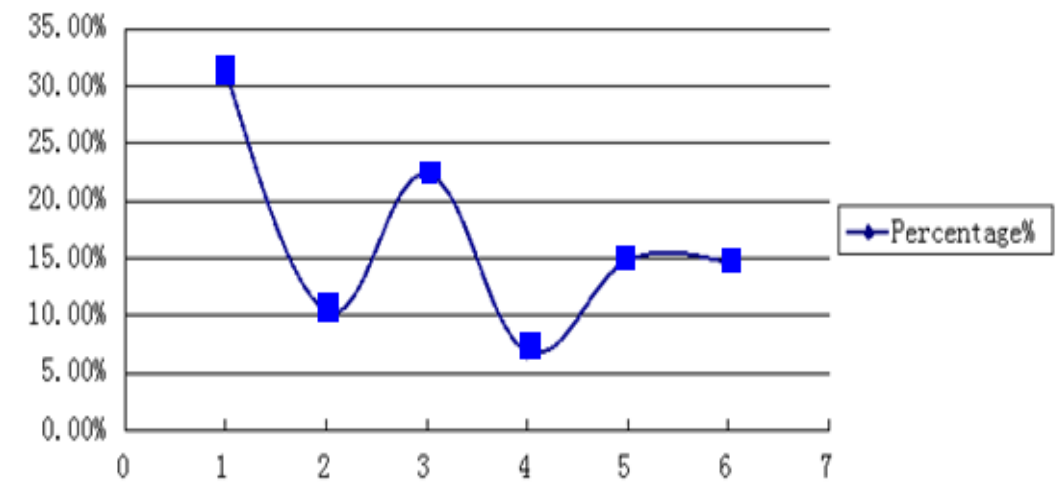

Fig. (3). The results.

By (Table $\mathbf{8}$ and Fig. 3) analysis, it is clear that the number of Chinese amateur athletes participants is the most important factor of affecting Chinese amateur basketball undertaking development, its weight is $31.4 \%$, next are state investment, athlete consumption situation, athlete age, participant purposes and participant income. 


\section{CONCLUSION}

Firstly, through interviewed and investigated experts statistics, the paper gets that among the interviewed experts, professors occupy $41.7 \%$, associate professors occupy $36 \%$, which makes the paper more convincing, lets research results to be more representative; And meanwhile, the paper interviewed experts make evaluation on recent years Chinese amateur basketball undertaking reformation effects, most of which think Chinese amateur basketball undertaking conforms to Chinese national conditions, but it still needs to continue to deepen reformation according to practical situations. Secondly, for Chinese amateur basketball participants weekly exercises situation, it makes analysis and finds that as resident life becomes more and more rich, the number of residents that participate in basketball is increasing, weekly exercises times are also increasing, which guarantees for Chinese basketball clubs development. Finally, the paper utilizes fuzzy AHP method to research on Chinese amateur basketball undertaking development, and analyzes Chinese amateur basketball undertaking development influence factors as the number of amateur athletes, state investment, athlete consumption situation, athlete age, participant purposes as well as participant income, it gets that the number of Chinese amateur athletes participants is the most important factor that affects Chinese amateur basketball undertaking development and its weight is $31.4 \%$.

\section{CONFLICT OF INTEREST}

The authors confirm that this article content has no conflict of interest.

\section{ACKNOWLEDGEMENTS}

None declared.

\section{REFERENCES}

[1] S. Huang, "Research on chinese men's basketball team's preparation against europe and american teams in the london olympic games," China Sport Science and Technology, vol. 48, no. 2, pp. 29-34, 2012.

[2] H. Li, "Correlative analysis on technical statistics and competition result of our man's national basketball team," China Sport Science and Technology, vol. 43, no. 4, pp. 72-76, 2007.

[3] J. Wen, "Seek the countermeasure and the margin of the technique of chinese men basketball team from the $28^{\text {th }}$ olympic games," Sport Science And Technology, vol. 27, no. 2, pp. 31-33, 2006.

[4] P. Yang, J. Liu, and Z. Yu, "Analysis of movement laws of factors leading to victory in basketball matches," Journal of Wuhan Institute of Physical Education, vol. 39, no. 10, pp. 82-85, 2005.

[5] H. Zhang, and D. Liang, "Correlation between ball possession in different areas and victory or defeat in the $18^{\text {th }}$ football world cup," Journal of Shenyang Sport University, vol. 28, no. 1, pp. 106-109, 2009.

[6] D. Zhou, "The technical analysis on chinese basketball association and italian lega basket serie a based on gray system and other mathematical methods," Sport Science And Technology, vol. 28, no. 1, pp. 32-35, 2007

Received: September 16, 2014 